\title{
Síntese das Artes na Arquitetura de Oscar Niemeyer
}

\section{Synthesis of The Arts in Oscar Niemeyer's Architecture}

\author{
Magda M. Melo ${ }^{1}$
}

\section{Resumo}

O presente artigo desenvolve o conceito integração das artes na arquitetura de Oscar Niemeyer. Este fenômeno possui um valor artístico que contribui ativamente na construção e desenvolvimento de um sistema cultural cuja importância está sendo averiguada. Consiste numa análise crítica e interpretação de algumas particularidades estilísticas relacionadas ao conceito e que se evidenciam como soluções específicas aos problemas originados das intenções do arquiteto.

Palavras-chave:- Oscar Niemeyer, síntese das artes, arquitetura moderna brasileira.

\begin{abstract}
This paper aims to develop the arts integration in Oscar Niemeyer architecture. This phenomenon has an artistic value wich contributes to a cultural system construction and development, whose importance is under investigation. It consists of a critical analysis as an interpretation of some stylistics details related to the concept, evidenced as specific solutions to problems originated by architect's intentios. Key words: Oscar Niemeyer, synthesis of arts, Brazilian modern architecture.
\end{abstract}

\section{Síntese das artes na arquitetura de Oscar Niemeyer}

Quando um arquiteto projeta um edifício e olha seus desenhos na prancheta, ele vê a planta projetada como obra já construída. Em transe, se o projeto o apaixona, ele nela penetra curioso, a examinar formas e espaços livres, a considerar os locais onde pensou um painel mural, uma escultura ou um simples desenho em preto e branco (NIEMEYER, 1988, p. A-3).

\section{Síntese das Artes}

O tema síntese das artes não é novidade. $\mathrm{O}$ relacionamento entre a obra de arte e a arquitetura tem variado de diferentes modos, e oscila de acordo com as épocas e os lugares. Podemos afirmar que, em toda a história da Humanidade, existem exemplos que idealizam coordenar todas as artes para alcançar um conjunto harmonioso.

No passado a pintura, escultura e arquitetura eram inseparáveis, com seus significados mutuamente enlaçados. Uma unidade de criação entre arquitetos, pintores e escultores, objetivando a construção de algo monumental e simbólico.

Recente é a habitual divisão entre arte e arquitetura, produto da especialização do século XVIII, quando o tradicional método das belas-artes isolou cada arte no seu sistema disciplinar.

\footnotetext{
1 Arquiteta formada pela Universidade Estadual de Londrina - UEL, professora da Universidade Paranaense - UNIPAR, doutoranda em História da Arte pela Universitat de les Illes Balears - UIB, Espanha. email: magda@ unipar.br
} 
A arquitetura não é uma arte independente. Sempre empregou a pintura e a escultura como elementos somados para a construção de um estilo artístico. Na síntese das artes, todas as artes físicas - visuais e arquitetônica - são unidas, visando a conformar um ambiente harmônico para a sobrevivência humana:

(...) através da arte da arquitetura o ser humano cria um ambiente para si próprio; ele forma o espaço. Através da arte da escultura o ser humano povoa esse ambiente, esse espaço, com materializações da sua própria percepção de qualidade de ser vivo, quel é sobretudo a característica da existência potencialmente capaz de agir. Através da arte da pintura a humanidade cria a ilusão de todo tipo concebível de ambiente e todo tipo de efeito em relação a estes ambientes (DIAMONSTEIN,1981, p. 17).

As artes plásticas, a pintura, a escultura e, incluímos, a arquitetura modernas possuem seus limites preservados. Não era deste modo na Antiguidade:

(...) no começo não havia nem arquitetura nem escultura, como artes distintas, mas uma forma completa que de preferência deveríamos chamá-la de monumento. Ambas, arquitetura e escultura, podem ser concebidas como evoluídas de uma unidade original, e de forma alguma é possível descrever esta entidade original como essencialmente arquitetônica ou essencialmente escultura(READ, 1977, p.5).

O trabalho do arquiteto moderno concentrou-se em proporcionar ao edifício, com seus elementos construtivos e tipológicos racionalizados, uma categoria de grandeza semelhante à obra antiga, com aquela feliz união entre as partes. Na integração entre as artes, todos os elementos relacionam-se formando uma unidade harmônica, de valor maior que sua simples justaposição.

Para a arquitetura moderna, a síntese das artes significa que a pintura e a escultura tornam-se parte integrante na composição arquitetônica, mas conservam seus valores estéticos independentes e intrínsecos. Significa que cada componente possui sua própria função e cumprem uma unidade estética, complementando-se.

O arquiteto Jose Luis Sert delineou três possibilidades de combinar a pintura e a escultura com a arquitetura: a aproximação integral, na qual o arquiteto assume o papel do artista, ou onde existe uma análoga percepção íntima entre a arte e a arquitetura. Sert referia-se à Renascença ou Art Nouveau, na qual o arquiteto também se torna o escultor ou pintor, submetendo as artes menores sob uma fundação arquitetural, obrigando as artes na direção de um comum objetivo artístico (LUM, 1999, p. 141).

Numa segunda possibilidade de combinação, as artes seriam aplicadas ao edifícios como elementos decorativos somente para melhorar a composição arquitetural. Nesse caso, a linguagem visual do artista é pré-ordenada pela arquitetura. A colaboração desta sorte, que trata a arte como ornamento, requer a mão do arquiteto ditando o estilo e o teor da obra agregada.

Conforme as diferentes direções da arte abstrata e da arquitetura moderna, a terceira possibilidade, a de independência mútua, seria a mais promissora. Respeitando as diferentes tendências visuais, seria uma cooperação recíproca simpatizante das artes e da arquitetura, na qual os ideais pessoais estariam preservados dentro de uma estrutura global.

\section{Síntese das artes e arquitetura moderna}

A revolução da arquitetura moderna trouxe o fim do decorativismo e o surgimento da parede branca. Os arquitetos modernos despojaram as paredes de todos os vestígios de épocas anteriores.

Assim, tudo que é considerado como uma coisa em si mesmo, como única, deve ser observado (...) como um complexo. Reciprocamente, tudo num complexo deve ser visto como parte do mesmo: como parte do todo. Então sempre veremos relações e sempre perceberemos uma coisa pela outra (MONDRIAN apud NELSON, 1996, p. 70).

A arquitetura racionalista passa a buscar uma pureza construtiva e excluem da configuração do 
edifício todos os elementos que não fossem sinceramente necessários às funções do habitar e da arte construtiva, e estivessem adaptados aos novos sistemas racionais e industrializados do mundo contemporâneo. "A arquitetura moderna ... queria que todo prazer arquitetônico derivasse do encontro puro com a necessidade" (DREXLER, 1981, p. 3). A arte moderna, que pôs a considerar o espaço como função, baniu e desprezou a arte dela mesma (ARGAN, 2000, p.156).

Desse modo, a obra de arte que vinha gradualmente adquirindo independência do edifício, torna-se elemento ilegítimo da arquitetura moderna racionalista (ROWE, 1978, p. 43). Todo o esforço dos estilos, ao longo da história, no sentido de transcender a necessidade, cederam como procedimentos sem valor. A eliminação da obra de arte da arquitetura significou a interrupção com anos de tradição.

Os arquitetos, sob o lema funcionalismo, acreditavam que a arte não era mais necessária. A estandardização dificultou qualquer manifestação individual de sentimento. A industrialização distanciou a arquitetura da arte e da estética e fê-la concentrarse na realidade social e material, no mundo prático. Era o período que negava a emoção que provinha da obra de arte.

Entendemos que a arquitetura moderna surgiu pelos arquitetos desgostosos com as condições artísticas anárquicas da sua época. Houve uma intrincada relação entre o ornamento e a decoração de um edifício e sua funções práticas.

Apesar das teorias dos pioneiros da arquitetura moderna que nunca pretendiam eliminar a arte da arquitetura, seus seguidores, por incapacidade ou engano, sistematicamente rejeitaram qualquer procedimento que não objetivasse a necessidade material ou funcional do edifício.

\section{Oscar Niemeyer}

Nenhum arquiteto brasileiro é tão lembrado quando nos referimos ao tema síntese das artes quanto
Oscar Niemeyer. Destaca-se dos demais colegas arquitetos pela presença coerente e contínua desta idéia desde seus primeiros trabalhos.

Le Corbusier foi, sem dúvida, paradigma para a construção do pensamento moderno no Brasil e conseqüentemente referência imediata no que se refere à integração das artes. Sendo mestre de Niemeyer, é responsável pela fomentação deste sistema na qual a obra de arquitetura relaciona-se com as demais artes.

Em 1952, em uma conferência internacional de artistas promovida pela UNESCO, Le Corbusier discutiu esse tema. O título da exposição era "Canteiro de síntese das artes maiores":

Trata-se de um problema limitado a um objetivo compreensível;

Fazer surgir de uma obra construída (arquitetura) "presenças" provocadoras de emoção, fatores essenciais do fenômeno poético.

Portanto essencial e exclusivamente resultando da presença comum da arquitetura, da pintura, da escultura, indissociavelmente ligadas pela harmonia, pela disciplina, pela intensidade.

A arquitetura estando hoje totalmente revolucionada em suas bases, a pintura e a escultura só podem ser de mesma natureza. (Le Corbusier apud SANTOS,1987, p. 239).

A primeira questão deste discurso sintetiza o que Niemeyer pratica em sua obra: a construção espacial fornecendo emoção estética. Para Le Corbusier (apud ESPINOSA, 1986, p. 89), a arquitetura é um estado de relações emotivas dedicado a produzir gozo espiritual: "a arquitetura tem que comover".

A segunda questão é um tema que não foi tratado por Niemeyer, que é a adequação da arquitetura às artes de vanguarda, sem que fosse permitido unir poéticas com objetivos distintos daqueles defendidos pela arquitetura moderna.

Niemeyer nunca defendeu este princípio. As obras dos artistas convocados geralmente estão imbuídos 
de uma característica diversa da arquitetura, tanto na forma quanto respeitante à narração. Esse fato decorre da poética fundamentada no elemento de contraste. Sem importar-se que a arte possua uma poética coincidente com a sua arquitetura, mas abordando-a como matéria que contribua ao jogo de contrastes, estimulando e contradizendo sua obra purista.

Le Corbusier influenciou diretamente Niemeyer no projeto do prédio do Ministério da Educação e Saúde, a primeira aplicação tangível do conceito moderno "integração das artes" no país. Podemos afirmar que este projeto tornou-se referência para toda a produção de arquitetura moderna brasileira:

Entre nós, lá pelo ano de 1936, graças à intervenção de Gustavo Capanema, então ministro da Educação e Saúde, a velha interação entre arquitetura e arte começou a ser recuperada; isso ocorreu quando, interessado pelos problemas das artes e da cultura, Capanema convocou para colaborar na construção do edifício sede do ministério os mais renomados artistas do país, enriquecendo-o com grandes murais de Portinari e escultura de Bruno Giorgi, Celso Antônio, Lipchitz. Esta volta ao passado, tão desejada, passou daí em diante, a atuar em nossa arquitetura que, em alguns casos, assumiu sua etapa superior de obra de arte. (NIEMEYER, 1994, p. 4).

Com as preocupações de adaptação desta nova arquitetura às condições locais, Le Corbusier aconselha o uso do azulejo na composição de painéis. O azulejo, mosaico azul, que era intensamente empregado nos edifícios coloniais, passa expressar a afirmação da personalidade brasileira dentro da modernidade. Serviria com suporte à novas expressões plásticas e assegurava às paredes proteção eficaz contra a excessiva umidade do Rio de Janeiro. A prática da utilização desse material havia sido rejeitada por arquitetos racionalistas que, preconceituosos, encaravam-no como um recurso meramente decorativo e comprometido com o passado.

Ora, o revestimento de azulejos no pavimento térreo e o sentido fluido adotado na composição dos grandes painéis têm a função muito clara de amortecer a densidade das paredes a fim de tirar- lhes qualquer impressão de suporte, pois o bloco superior não se apoia nelas mas nas colunas. Sendo o azulejo um dos elementos tradicionais da arquitetura portuguesa, que era a nossa, pareceunos oportuno renovar-lhe a aplicação (COSTA, 1962, p. 257).

Niemeyer emprega as obras de arte com a função de ornamento, mas diferente do propósito meramente decorativo. A pintura e a escultura, mesmo fazendo parte da composição arquitetônica como algo anexado, preservam seus valores estéticos independentes e convencionais. Como é um arquiteto moderno, não encontraremos na sua produção elementos de efeitos plásticos simplistas.

Percebemos que Niemeyer interessa-se em definir a localização da obra de arte quando ainda no processo projetual. Podemos reconhecê-la ainda no croqui, algumas vezes num desenho avançado definindo o tema da obra, se é uma escultura reclinada ou vertical. O que significa que durante o exercício da criação o arquiteto já está identificando como e quem irá executá-la. É uma antevisão do que será realizado.

Somente depois da consumação da obra arquitetônica em toda a sua pureza o arquiteto definirá exatamente quais serão as obras de arte. A ação de escolha é em seguida à conclusão da obra arquitetônica. É uma ação posterior, anexada, e realizada por outro idealizador que ajusta sua intervenção no campo de criação de Niemeyer.

A obra de arte tem uma função específica: criar beleza, monumentalidade e um sistema de hierarquização formal sobre os elementos construtivos do edifício. O uso deste recurso numa arquitetura pura como a de Niemeyer é sobre a base do contraste.

As pessoas desejam edifícios que representem sua vida social, cerimonial, e comunitária. Querem que os edifícios sejam mais que uma realização funcional. Buscam a expressão das suas aspirações na monumentalidade, para alegria e excitação (GIEDION, 1958, p.270). 
Monumentalidade nasce a partir da eterna necessidade humana de criar símbolos para suas atividades, para seu fado ou destino, para suas crenças religiosas e suas convicções sociais. Toda época tem o ímpeto de criar símbolos na forma de monumentos, os quais, de acordo com o significado latino "coisa que lembra", significam algo a ser transmitido para gerações posteriores.

Existem três maneiras em que Niemeyer utiliza a arte na sua arquitetura: os relevos nas superfícies dos edifícios com uma função ornamental; os azulejos e as pinturas murais, onde a arte desmaterializa a parede; e a escultura que está no exterior, mas se relaciona com o edifício ao fundo pois mantém uma distância definida segundo regras de composição.

As obras escolhidas ou encomendadas agradam a um gosto popular, fazendo com que o espectador ingênuo se identifique com sua arquitetura erudita. Dessa forma explica-se porque a arquitetura de Niemeyer possui um nível de comunicação tão amplo.

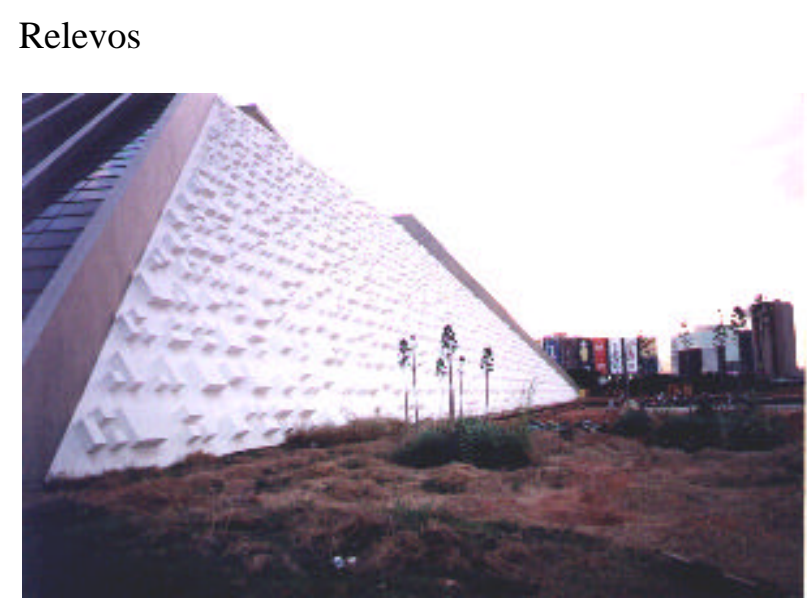

Figura 1. Relevo de Athos Bulcão no Teatro Nacional

Os relevos possuem características invariáveis: partem de um desenho geométrico simples com poucas variações de formas, de linhas retas ou curvas, e com uma única cor. O artista cria uma composição variada sobre um módulo reticulado, proporcionando uma movimentação rítmica. Inspirado pelos movimentos da vanguarda russa, percebemos influências de suprematistas como Malevitch.

A arte concreta renuncia a um expressionismo que sempre foi característica de uma obra de arte individual. Sua investigação no campo da plástica, centrada na forma, na cor, no espaço e a aversão a qualquer representação da realidade, facilita a realização de um trabalho de equipe com o arquiteto, integrando a obra à arquitetura para a criação de um ambiente significativo.

Os painéis laterais do Teatro Nacional Cláudio Santoro correspondem à maior obra de integração arte-arquitetura na produção de Niemeyer. Foi entregue ao artista plástico Athos Bulcão ${ }^{2}$. para que interviesse nas duas fachadas de maior extensão.

A questão crucial foi atender o pedido do arquiteto: "algo que fosse ao mesmo tempo pesado e leve". Buscando solucionar tal antagonismo, $o$ artista criou uma combinação de relevos em concreto - quadrados e retângulos aplicados numa relação geométrica. Os relevos referem-se àquelas vibrações ópticas produzidas pelo impacto da luz incidente e sombra das formas como nas antigas pirâmides egípcias.

É comum Niemeyer indicar alguns princípios da composição da obra aos artistas para certificar um resultado ajustado com as intenções do projeto, principalmente nas encomendas dos painéis e dos murais.

Um dos fenômenos que formaram a arte moderna é a tendência ao incondicional e à libertação. Um desejo da arte e todas as suas manifestações de se conformarem completamente puras, ou seja, uma autonomia de elementos ou componentes.

A execução de murais com cores puras e formas geometrizadas foi possível a partir da liberdade adquirida pela arte moderna. $\mathrm{O}$ gênero abstrato veio a oferecer novas possibilidades de aplicações

\footnotetext{
2 Athos Bulcão em entrevista à autora.
} 
plásticas na arquitetura ocupando a pintura mural - a cor emancipou-se do objeto, e permitiu uma liberdade de disposição de linhas e de formas. O tom puro passou a ter uma ação nova e completamente independente da pintura que, antes do abstracionismo, estava encarregada de contê-la ou de trazê-la para o quadro conforme uma mimese ilusionista. A arte de estilo realista viola a integridade da parede.

\section{Azulejos e pinturas murais}

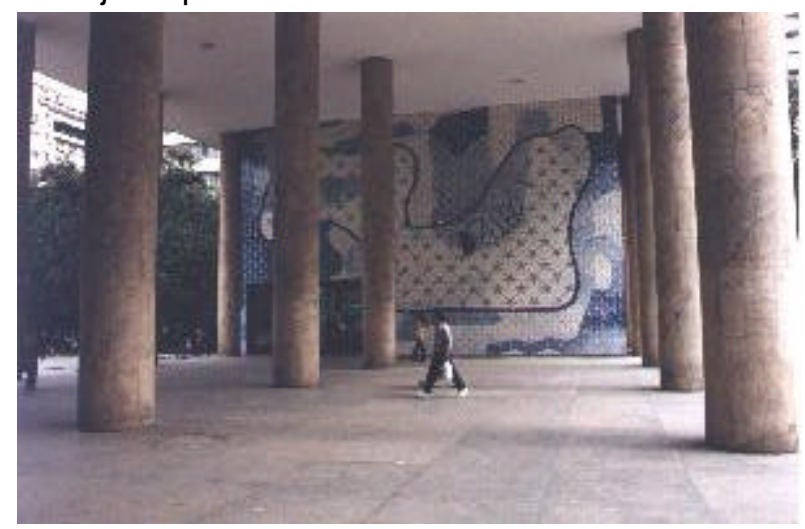

Figura 2. Azulejos de Portinari no Ministério da Educação e Cultura

A arquitetura sempre foi uma arte abstrata. Desde as primeiras construções ela se utiliza de formas geométricas distantes das encontradas na natureza. Por outro lado a pintura e a escultura formadas por padrões não miméticos surgiu mais intensamente no séc XX. Com o abstracionismo a arte abandonou os temas representativos da natureza, e pôde concentrar-se em questões antes pretencentes à arquitetura (problemas de forma, cor, volume e espaço), o que veio à propiciar uma integração entre elas. Desse modo, a arte passou a fornecer os elementos férteis para a organização do espaço arquitetônico. A arte moderna teve, assim, um papel relevante na organização do espaço.

A policromia tem um poder de criação espacial na arquitetura moderna. É considerada um elemento manipulador do espaço e da forma. A participação do artista deve ser dirigida a proporcionar qualidade por meio do uso deste recurso, conforme as necessidades de luz e superfície que o arquiteto venha a exigir.
O uso da cor está direcionado a enfatizar a plasticidade da forma, em proporcionar independência ao plano, teto ou parede. Qualquer cor aplicada em um elemento torna-o capaz de uma mobilidade que desvia sua rigidez. É possível sem claro-escuro, sem modelação, obter resultados ilusionistas como profundidade e dinamismo.

A presença da obra pictórica transforma o espaço, na intenção de proporcionar uma nova realidade. De maneira construtiva a obra de arte permite corrigilo: classificar as paredes em uma hierarquia, impor dinâmica aos planos arquitetônicos, seria um meio de transformar o espaço qualificando-o visualmente de maneiras distintas.

A policromia arquitetônica é outra coisa; ela se apossa de toda a parede e a qualifica com a potência do sangue, ou o frescor da pradaria, ou o clarão do sol, ou a profundeza do céu ou do mar. Que forças disponíveis! É a dinâmica, que eu poderia escrever muito bem a dinamite, com meu pintor introduzido na casa. Se uma parede assim fosse azul, ela fugiria; se fosse vermelha, manteria o plano, o mesmo ocorrendo caso fosse castanha; posso pintá-la de preto ou de amarelo.(LE CORBUSIER, 1984, p.64).

Um dos diálogos que arquitetura e a pintura mantêm entre si é acerca de uma continua oscilação entre plano e profundidade, entre a solidez da matéria e a transparência como resultado óptico. Não é uma profundidade criada pelo recurso da perspectiva ilusionista, mas por um espaço virtual produzido pela obra. É como se a pintura fosse uma substituta de janelas, que, pelos seus recursos pictóricos, elimina a existência da parede.

O mural dilui o plano, dilui a materialidade da parede. Esta noção de transparência não significa uma matéria em que se pode ver através - já que o mural é opaco - mas corresponde a que Colin Rowe denomina transparência fenomenal, uma transparência encontrada na relação de diversas espacialidades.

As figuras são dotadas de transparência; isto é, elas são capazes de se interpenetrar sem uma 
destruição ótica de uma pela outra... Transparência significa uma percepção simultânea de diferentes localizações espaciais. O espaço não só recua, mas flutua numa contínua atividade (COLIN ROWE apud MONTEIRO, 1989, p.124).

O cubismo e o seu descendente o purismo, e o De Stijl, foram pólos formalistas da primeira vanguarda modernista e tornaram-se igualmente aceitos pelos arquitetos em suas obras. Para Paul Damaz (1956, p. 39), esta época favorecia a colaboração das artes e a pintura e a escultura, agora abstratos, encontram-se pela primeira vez em íntima comunhão com arquitetura, a arte que é por si mesma abstrata. Então o aparecimento de formas geométricas e abstratas na pintura identifica-se com a composição formal da arquitetura moderna.

Léger (1989, p.117) acredita que a aplicação da arte abstrata convém perfeitamente para as grandes decorações murais. Esse fato é devido à possibilidade que o artista adquiriu em poder manipular a cor de forma livre, facilitando o acordo da obra com a necessidade do espaço arquitetural. A cor, que numa obra representativa estava distribuída em detalhes, em respeito a um compromisso com a realidade, adquire liberdade e intensidade plástica na manipulação do espaço.

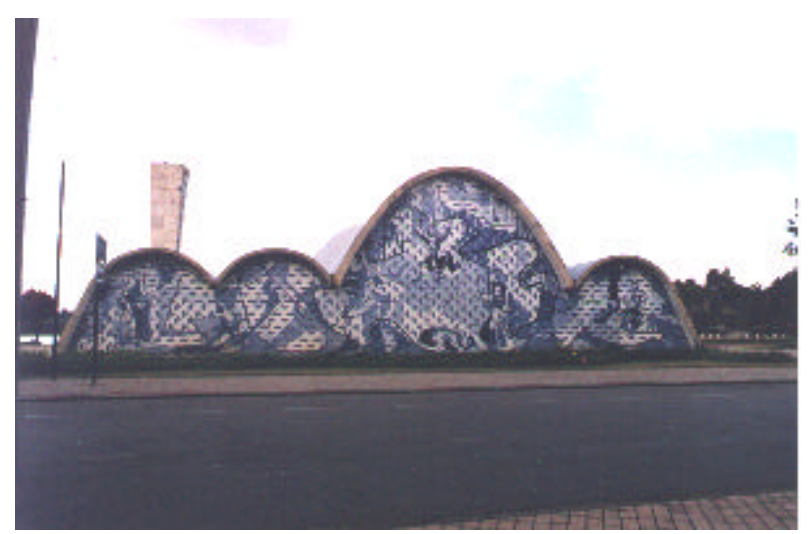

Figura 3. Azulejos de Portinari na Capela São Francisco de Assis na Pampulha
A Capela de São Francisco possui a mais conhecida obra de arte do complexo da Pampulha, o painel de azulejos de Cândido Portinari, com motivos religiosos alusivos à trajetória de São Francisco de Assis. É nesta capela que percebemos que a integração das artes, colaboração entre artistas e arquitetos, teve o seu maior êxito

A utilização de painéis de azulejos em azul e branco já havia sido feita no prédio que abrigava o Ministério da Educação e Saúde, mas não com um caráter narrativo.

A conjunção da composição fundamentalmente figurativa, com a estrutura arqueada, expressa a originalidade de um impetuoso acesso de independência criativa e afirmação da personalidade brasileira dentro da modernidade. É possível encontrar aqui um simbolismo popular mesclado a uma invenção técnica e plástica da linguagem moderna.

Muitos críticos justificam o uso do azulejo como uma referência à tradição decorativa da arquitetura colonial portuguesa do interior das igrejas barrocas. No entanto, ao ser questionado pelo prof. Carlos Lemos (1984, p. 171) acerca desta suposta tradução das manifestações históricas na arquitetura moderna brasileira, o próprio Niemeyer respondeu que a exigência desse tipo de preocupação na arquitetura moderna era bobagem, pois azulejo, enquanto material obrigatório, deveria ser esquecido.

Concluímos que o uso do azulejo resume-se às características próprias do material - um elemento que cumpre a função de suporte de uma pintura, resistente ao tempo, e com qualidades cedidas à manipulação da forma e espaço - leveza, brilho, diluição do plano, opacidade.

Para Mark Rothko, pintor da escola de Nova Iorque, o mural serve para satisfazer a ambição do artista em produzir obras em grande escala. Diferente do afresco, ilusório, o mural tem a capacidade de afirmar a noção de presença, de delinear o espaço arquitetural sobre o espaço pictórico. 


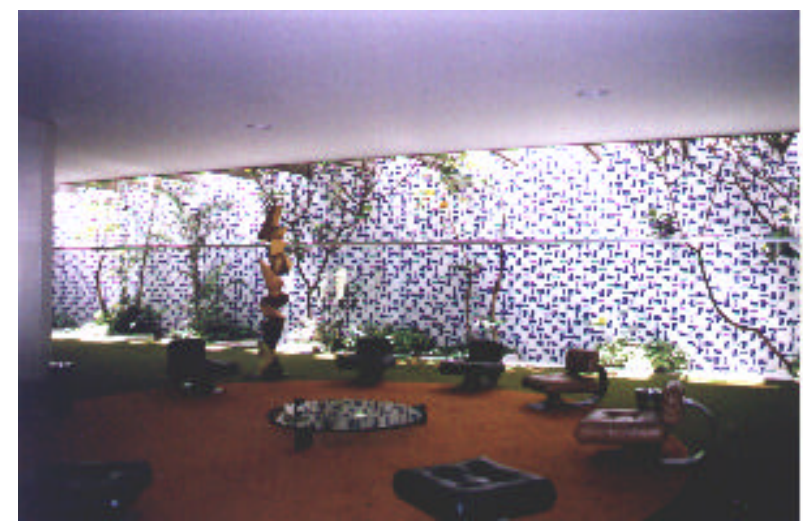

Figura 4. Azulejos de Athos Bulcão no Congresso Nacional

É certamente nas obras de Brasília que o painel de azulejo, com Athos Bulcão, alcança seu ponto mais alto de criação. É o artista que melhor encerrou a presença desta cerâmica na arquitetura moderna.

É considerado, por muitos, um ornamentador, por seus trabalhos de integração arquitetônica possuírem pouco caráter individual, em consequiência do vínculo com as propostas estéticas solicitadas pelos arquitetos. Por meio das obras de Athos Bulcão, a arquitetura de Niemeyer alude ao tema do ornamento e da inserção da obra de arte simultaneamente (MONTEIRO, 1989, p.164).

As obras de Athos Bulcão são classificadas como adorno, pois estão sempre conectados a um determinado local, imposto pelo arquiteto. $\mathrm{O}$ artista trabalha subjugado à arquitetura e não se projeta individualmente. Seus painéis não possuem força suficiente para libertar-se da arquitetura.. Perderiam a vitalidade se desconectados.

Athos Bulcão não se ocupa com os aspectos artesanais da pintura sobre azulejo, mas de suas possibilidades compositórias. Procura aliar a técnica do azulejo à produção industrial com as necessárias exigências econômicas. Enfrenta o moderno na sua dimensão industrial. "Recusei-me sempre à imitação dos desenhos 'antigos' de épocas em que dominava o artesanato. Os belos arabescos a bico-de-pato de outrora não pode ser transformados em 'carimbos'.
Isso, penso, eqüivaleria a uma máquina de escrever que imitasse a caligrafia de Luiz XIV “(BULCÃO, s. d, s. p.).

Na composição o azulejo representa um elemento frio, sem relevo, plano. $\mathrm{O}$ artista não pretende neutralizar o quadriculado do suporte. Athos Bulcão compreende o material como um módulo com inúmeras possibilidades de composição. A liberdade de arranjos transforma-se na potencialidade de criação.

Athos Bulcão considera que sua obra está inserida em um espaço arquitetônico e não pretende realçála individualmente, mas trabalha a partir da arquitetura com o comprometimento em valorizá-la mantendo uma unidade de conjunto.

Ele mesmo, em entrevista, compara-se a um membro de uma orquestra, operando seu instrumento, sendo maestro o arquiteto que coordena e toma as decisões para alcançar harmonia.

\section{Esculturas}

Tanto a pintura quanto a escultura possuem um papel de coadjuvante. Na designação das obras, Niemeyer nunca procurou uma qualidade máxima de autonomia como obra de arte. De outro modo, se existisse, tornaria prejudicial ao seu jogo de equilíbrio formal, introduzindo um elemento dissonante na semântica purista de sua arquitetura. $\mathrm{O}$ modo preciso com que escolhe e coloca as obras de arte, atribuindo a função de um elemento arquitetônico, é similar à arquitetura clássica.

Num sistema integrado, a obra de arte e a arquiteturasolicitam-se mutuamente.

O ajuste é uma relação de concordância e aceitabilidade recíproca entre estes dois elementos. Deve-se estabelecer entre a obra de arte e a arquitetura uma coexistência, sem haver prejuízos.

As esculturas, obras que na sua maioria são escolhidas e não encomendadas, são adaptadas ao lugar eleito, mas sempre mantêm o princípio como 
obra de arte individual, demarcando seu próprio campo. Nunca se tornam ambíguas, pois não se confundem com a arquitetura.

A escultura é uma habitual figura de contraste na arquitetura de Niemeyer, que não só a recolheu como também abasteceu-se de uma imagem como um modo de confrontar as formas abstratas do edifício e as naturalistas da obra de arte. Do mesmo modo que Mies van der Rohe no pavilhão de Barcelona de 1929, Niemeyer domina o espaço utilizando um elemento que exerce a função de ponto focal.

Segundo Bruno Zevi (1978, p.120), as estéticas tradicionais enfocam alguns princípios que correspondem à composição arquitetônica. Um desses conceitos: a ênfase ou a acentuação. Em todas as composições, é necessário um centro de interesse visual, um ponto focal que prenda a vista. Nos projetos de Niemeyer a obra de arte é que irá tomar o caráter de centro de atenção.

Na sua poética de formas mínimas, a obra de arte situa-se como ponto focal, como parte convergente na composição, adequada ao programa de redução dos elementos construtivos empreendido pelo arquiteto.

Nos palácios, o espelho d'água se oferece com o propósito de realçar a obra da arquitetura. A solução de isolar os palácios num espelho d'água, proporciona uma leveza e uma nobreza ao edifício tal qual um castelo contemporâneo. $\mathrm{O}$ espelho d'água esconde o pedestal, causando a ilusão da escultura flutuar.

No Palácio da Alvorada, o escultor Alfredo Ceschiatti versa sobre duas mulheres nuas dispostas simetricamente. "As Banhistas" é uma obra fundida em bronze, escura e volumosa, contrastando com a arquitetura clara e reluzente do palácio ao fundo. Nessa obra, cheios e vazios, formas e ritmos em absoluto equilíbrio, fazendo uma analogia direta com as colunas e seus vãos.

Diante da fachada principal do Palacio do Itamarati, o espelho d'água torna-se mais amplo, abrigando a escultura em um jardim de plantas aquáticas do paisagista Burle Marx. De Bruno Giorgi, "Meteoro" é uma exceção onde o abstrato encena com o abstrato. O conjunto composto pelo edifício ao fundo, mais a escultura, é formado por uma relação de ritmos e arestas. A unidade dos elementos contrastantes torna a composição vigorosa. A oposição entre escuro e o claro, cheios vazios, linhas horizontais e verticais, o abstrato e o figurativo, é que torna a obra viva.

A forma plástica da escultura providencia um contraponto ao ritmo forte dos arcos do palácio; a escultura lisa, leve e branca do mármore se contrapõe ao edifício ao fundo, com os arcos em concreto aparente em cor ocre e a textura rugosa conferida pelas formas.

A arquitetura de Niemeyer, fundamentalmente, manipula o conceito de contraste. A intenção é sempre encontrar uma relação de equilíbrio entre os elementos que participam da forma final: uma obra figurativa em oposição a um prisma puro, uma superfície transparente em oposição a um painel opaco.

Um dos problemas da relação entre arquitetura e artes plásticas é o suporte, ou seja, o receptáculo onde a arte é deitada, é colocada. Na escultura clássica, era tão neutro quanto a moldura de um quadro. A anulação do suporte é uma dessacralização da arte: arte retirada do seu pedestal e de sua pompa.

A obra de arte isolada, seja uma pintura de cavalete ou uma escultura, é um objeto completo, capaz de subsistir por si mesmo. O encontro da obra com o ambiente envoltório irá gerar um campo dramático, um campo de confronto máximo entre a natureza e o artifício, entre a realidade e a fantasia, do choque do orgânico com o abstrato, de uma aristocrática arte com a vida ordinária.

Para a arte sobressair, mostrar-se diferente das coisas banais que a circundam, tem que se tornar intangível, sacrossanta, tem que se pôr em seguro num nicho, ou pedestal, ajustando-se harmoniosamente ao ambiente. 


\section{Conclusão}

A arte pode complementar a arquitetura, potencializando seus efeitos estéticos, por meio da confrontação, da distinção ou relevância em concordância com a composição. Pode, ainda, combinar diferentes partes arquiteturais num todo. A arte completa e anima o vazio, superfícies sem vida que se encontram entre os elementos arquiteturais. Torna inteligível particulares elementos arquitetônicos, com consideração às suas atividades simbólicas e funcionais.

A síntese nas artes demanda uma coesão de crença e pensamento entre o arquiteto e os artistas. Se Le Corbusier não entregava a outros artistas seus projetos para incluírem obras de arte, ele mesmo executava seus murais, Niemeyer não se comporta do mesmo modo, pois não tinha propensão a artista completo. Para ele, a interpretação da expressão síntese das artes significou sempre agregar ao edifício as obras de artistas amigos.

Niemeyer organizou um time de artistas que participavam dos projetos desde os primeiros desenhos. Discutiam todos os problemas dos projetos nas suas minúcias, sem se concentrar num único problema, dividindo-se em determinadas áreas, mas considerando o projeto como um todo harmonioso. Para ele é certo que o arquiteto dá a sua opinião em cada problema, propondo soluções e checando com cada membro da equipe.

\section{Referências}

ARGAN, Giulio Carlo. Projeto e Destino. São Paulo. Ática, 2000.

ATHOS, Bulcão .Integration Architecturale. Géneve: Rousseu, s. d.

COSTA, Lucio. Sobre Arquitetura. Porto Alegre,Centro dos Estudantes Universitários de Arquitetura, 1962.
DAMAZ, Paul. Art in European architecture. New York , Reinhold Pub. Corp., 1956.

DIAMONSTEIN, Barbaralee (ed.). Artists \& Architects. New York, Whitney Library of Design, 1981.

DREXLER, Arthur. Transformaciones de la arquitectura moderna. Barcelona: GG 1981.

ESPINOSA, Elia. L'esprit Nouveau: Una estética moral purista y un materialismo romántico. México: Universidad Nacional Autónoma de México, 1986.

GIEDION, Siegdion. Architecture you and me. Cambridge: Harvard University, 1958.

LE CORBUSIER. A arquitetura e as belas artes. Revista Patrimonio Histórico e Artístico Nacional, Rio de Janeiro, v 19, p.55-57, 1984.

LÉGER, Fernand. Funções da Pintura. São Paulo, Nobel, 1989.

LEMOS, Carlos A. C.. Azulejos Decorados. Revista Patrimonio Histórico e Artístico Nacional. Rio de Janeiro, 20, p.171, 1984

LUM, Eric K. Architecture as Artform: Drawing, Painting, Collage, and Architecture 1945-1965. Massachusetts, 1999. Tese (doutorado) - Massachusetts Institute of Technology.

MONTEIRO, Kleber Ferraz. La forma en la Arquitectura de Oscar Niemeyer. Madrid, 1989. Tese (Doutorado) Escuela Tecnica Superior de Arquitectura. Universidad Politecnica de Madrid. 2 v.

NELSON, Robert S.; SHIFF, Richard (ed.). Critical Terms for Art History. Chicago, University of Chicago, 1996.

NIEMEYER, Oscar. O Memorial da América Latina e a Integração das Artes. Folha de São Paulo, São Paulo, 12 abr. 1988, p. A-3.

NIEMEYER, Oscar. Uma síntese de Liberdade Plástica. $O$ Povo, Fortaleza, 26 ago. 1994. Variedades, p.4.

READ, Herbert. The Art of Sculpture. Princeton, Princeton University Press, 1977.

ROWE, Colin. Manierismo y Arquitectura Moderna y Otros Ensayos. Barcelona, Gustavo Gili, 1978.

SANTOS, Cecília Rodrigues, et al. Le Corbusier e o Brasil. São Paulo, Tessela, Projeto Editora, 1987.

ZEVI, Bruno. Saber Ver a Arquitetura. São Paulo, Martins Fontes, 1978. 